\title{
SELF-PERCEPTION OF PRIMARY HEALTH-CARE STAFF ABOUT PHYSICAL ACTIVITY ON PRESCRIPTION: A QUALITATIVE SEMI-STRUCTURED INTERVIEW
}

\author{
Sergio Calonge Pascual ${ }^{1}$, Francisco Fuentes Jiménez ${ }^{2}$, Rosa Arnal-Selfa ${ }^{3}$, Susana \\ Belmonte-Cortés ${ }^{4}$, and Marcela González-Gross ${ }^{2}$ \\ ${ }^{1}$ Universidad de Valladolid Facultad de Educación \\ ${ }^{2}$ Universidad Politécnica de Madrid \\ ${ }^{3}$ Dirección Asistencial Enfermería DA Norte. Gerencia \\ ${ }^{4}$ Dirección General de Salud Pública. Consejería de Sanidad
}

November 23, 2021

\begin{abstract}
Rationale, Aims, and Objectives: Physical inactivity and sedentary levels represent one of the major threats to public health. Physical activity on prescription (PAP) is an emerging preventive and treatment resource for chronic diseases at Health-care Settings. This study aimed to analyze the self-perception at primary health-care (PHC) nurses and general practitioners (GPs) toward PAP implementation in PHC centers. Methods: Two semi-structured group interviews were performed separately, with five GPs and nurses working in the PHC system in the region of Madrid (Spain). An expert psychologist guided each semi-structured session. The interviews were transcribed verbatim and consensually analyzed using a mixed content analysis. Results: Half of the PHC staff considered themselves physically active and were convinced that physically active staff behavior could facilitate PAP with patients. Both GPs and nurses showed a lack of knowledge of exercise prescription but were interested in PAP and motivational training courses, as well as leadership or to collaborate under a multidisciplinary or interdisciplinary PAP approach. Some of the most relevant self-perceived PAP barriers were a confident method to measure sedentary and physical activity levels. Besides lack of staff awareness, time of consultation, and improving local community relationships and PAP policies strategies. Conclusions: There are some common self-perceptions, barriers, and facilitators among PHC nurses and GPs for PAP implementation. Following a socio-ecologic approach, this organizational data provides further insight to design a future cost-effective policy strategy to improve patient health and health-care system sustainability.
\end{abstract}

\section{Hosted file}

J. Eval. Clin. Pract_Main text file.docx available at https://authorea.com/users/447634/ articles/546589-self-perception-of-primary-health-care-staff-about-physical-activity-onprescription-a-qualitative-semi-structured-interview

\section{Hosted file}

J. Eval. Clin. Pract_Tables.docx available at https://authorea.com/users/447634/articles/ 546589-self-perception-of-primary-health-care-staff-about-physical-activity-onprescription-a-qualitative-semi-structured-interview 